\title{
Exclusión escolar: caso de una niña con parálisis cerebral en una institución educativa urbana marginal de Popayán*
}

\author{
School exclusion: case report of a girl with cerebral palsy in an \\ marginal urban school of Popayan
}

\section{Exclusão escolar: caso de uma menina com paralisia cerebral numa escola pública da cidade de Popayán, Cauca, Colômbia}

\author{
Luz del Sol Vesga Parra* \\ Luz Betty Pisso Pisso*** \\ Diana Carolina Villaquirán Hurtado ${ }^{* * * *}$
}

Recibido 24. 02. 2016 • Arbitrado 10. 03. 2016 • Aprobado 21.04. 2016

\section{Resumen}

El artículo presenta algunos resultados de una investigación cuyo propósito fue comprender el proceso de inclusión escolar de una niña con Parálisis Cerebral del grado tercero de básica primaria de una

Articulo presenta resultados de la investigación "Procesos de inclusión escolar de una niña con parálisis cerebral de grado tercero de la básica primaria de la institución educativa tomas Cipriano en la ciudad de Popayán, durante el año 2014-2015”. 07-2015-1. Las autoras desean dar expreso crédito y mención a la Corporación Universitaria Autónoma del Cauca por los espacios y tiempos facilitados para llevar a cabo esta investigación.

* Licenciada en Tecnología e Informática, Universidad Católica de Manizales; Magíster en Educación, Universidad del Cauca; Estudiante del Doctorado en Educación, Universidad del Cauca; Docente Investigadora de la Facultad de Educación de la Corporación Universitaria Autónoma del Cauca, Colombia, Integrante del Grupo de Investigación GICHIS y Coordinadora del Semillero de Investigación SEFAC de la Corporación Universitaria Autónoma del Cauca, solvesga@uniautonoma.edu.co

*** Tesista de la Licenciatura en Educación Preescolar, Corporación Universitaria Autónoma del Cauca; Integrante del Semillero de Investigación SEFAC de la Corporación Universitaria Autónoma del Cauca, Colombia, lubetty1991@hotmail.com

**** Tesista de la Licenciatura en Educación Preescolar, Corporación Universitaria Autónoma del Cauca; Integrante del Semillero de Investigación SEFAC de la Corporación Universitaria Autónoma del Cauca, Colombia, diana311090@hotmail.com 
institución educativa marginal de la ciudad de Popayán (Cauca). Esta investigación es de tipo cualitativo, basada en el método de la teoría fundamentada, donde se parte de la comprensión de la realidad escolar vivida por una niña en condición de discapacidad; una vez realizado el proceso de análisis de los relatos emergen algunas categorías, de las cuales se presentará en este artículo la categoría: "El sujeto sin voz", en la que se devela cómo la niña vive en una exclusión, incluso con ella misma. El artículo concluye cuestionando, a partir de lo encontrado, cuán lejos se está de alcanzar una verdadera educación inclusiva en los espacios escolares.

Palabras Claves: Discapacidad, escuela, inclusión escolar, niñez, parálisis cerebral.

\section{Abstract}

The article reports some results of an investigation that was oriented to understanding the process of school inclusion of a girl with cerebral palsy in the third grade from a marginal school in the city of Popayan, Cauca (Colombia). This investigation is qualitative and is based in the method of Grounded Theory in which we start from comprehension of scholar reality lived by a girl in a disability situation; once made the process of analysis of stories emerge some categories. In this paper we show the category: "Subject without voice", in which we show how the girl lives in an exclusion situation, even with herself. We conclude questioning, based on the findings, how far we are to reach a really inclusive education in the school environments.

Wordskeys: Disability, school, school inclusion, childhood, cerebral palsy.

\section{Resumo}

O artigo apresenta alguns resultados de uma investigação cujo propósito foi compreender o processo de inclusão escolar de uma criança 
com paralisia cerebral no Ensino Fundamental de uma escola pública da cidade de Popayán, Cauca, Colômbia. Esta pesquisa é de tipo qualitativo, baseada no método da teoria fundamentada, através do qual se pode compreender a realidade escolar vivida por uma menina num estado de deficiência física; uma vez feito o processo de análise das histórias, emergem algumas categorias, das quais se apresentará neste artigo a categoria: "O sujeito sem voz", onde se revela como a criança vive numa situação de exclusão, mesmo com ela. $\mathrm{O}$ artigo conclui perguntando, a partir do que foi encontrado, quão longe se está de alcançar uma educação verdadeiramente inclusiva nos ambientes escolares.

Palavras-chave: deficiência, escola pública, inclusão escolar, infância, paralisia cerebral.

\section{Introducción}

De acuerdo con Saldarriaga (2009), en los orígenes de la escuela el compromiso de la institución era generar procesos de "normalización"; los distintos eran rechazados por el sistema o sometidos a grandes castigos para llegar a un único proyecto de ser humano preconcebido en las características de la sociedad moderna: personas disciplinadas, obedientes, con moral y buenas virtudes; entonces, desde sus inicios, la escuela promovía radicalmente la exclusión de aquellos sujetos considerados como diferentes. Fueron los procesos históricos, acompañados de movimientos sociales y pedagógicos, los que llevaron a proclamar la Constitución Política de Colombia (1991), la cual, entre otras cosas, consagra el derecho fundamental de las personas a acceder a una educación de calidad, sin ningún tipo de discriminación; seguidamente, la Ley General de Educación (1994) rechaza la educación segregada de las personas en situación de discapacidad y se solicita trabajar por una integración escolar (Mantoan, 2005), permitiendo acceder a las personas en condición de discapacidad a las aulas regulares de cualquier institución educativa pública de Colombia.

Siguiendo las políticas públicas de aquel momento, algunas instituciones se atrevieron a permitir el acceso educativo a estudiantes que se 
encontraban en condición de discapacidad; sin embargo, la promesa de integración falló porque las aulas regulares no estaban preparadas para este cambio: ausencia de capacitación a los docentes, inexistencia de material didáctico, falta de prácticas pedagógicas distintas y acordes para los estudiantes con discapacidad (Comín, 2014). De este modo, en los últimos años se viene trabajando en el tránsito del concepto de integración educativa al de inclusión educativa, donde se priorizan procesos orientados a eliminar o minimizar las barreras que limitan el aprendizaje y la participación de todos los estudiantes, sin importar la condición en que se encuentren (Blanco, Aguerrondo, Ouane, y Shaeffer, 2000).

Este camino de la educación inclusiva se convierte en una oportunidad para garantizar "el derecho de la educación a todos, independientemente de sus diferentes particularidades" (Sarto y Venegas, 2009, p21), así como también tener en cuenta "las características, intereses, capacidades y necesidades de aprendizajes" de todos los estudiantes (Sarto y Venegas, 2009, p.15). Solo así se podrá avanzar hacia una transformación cultural en la sociedad, con respecto a todos los procesos de inclusión. Desde hace varios años, algunos miembros del sistema educativo colombiano vienen adelantando esfuerzos para que se cumpla la política pública de inclusión en las distintas realidades escolares; no obstante, los contextos educativos son complejos y aún se encuentran muchos niños y niñas en situación de discapacidad a quienes se les está vulnerando el derecho a recibir una educación de calidad en la que se potencien sus capacidades y no se resalten sus dificultades (UNICEF, 2001, p.5).

Por lo anterior, la investigación nos motivó a comprender lo que realmente estaba sucediendo con los procesos de inclusión en la vida escolar; para ello tomamos un caso específico de discapacidad: la Parálisis cerebral, entendida, según François, \& Martínez (2005), como una lesión originada a nivel cerebral y muscular, viéndose afectado el desarrollo de las habilidades de motricidad gruesa y fina de las personas; de este modo, al no originarse una buena conexión entre ellos, se da una 
condición que no permite un desarrollo pleno de crecimiento físico, ya que los niños que la padecen no pueden ejecutar tareas con facilidad, como: sentarse, correr, caminar, tener equilibrio, entre otros; los orígenes se presentan con más frecuencia durante el parto debido a la falta de oxígeno como causante principal.

$\mathrm{Al}$ revisar el estado del arte acerca de los procesos de inclusión de niños con parálisis cerebral, se encontraron algunas referencias tanto a los procesos de rehabilitación (Rubinstein, Ramalho y Camargo, 2002), como a procesos de salud y cuidados (Madrigal, 2004), la mirada proteccionista desde el entorno familiar (Canarin, Furtado, Alves, Pedroso, 2012) y la inclusión escolar (García y Restrepo, 2010; Acosta, y Arráez, 2014). Estas investigaciones muestran cómo la mayoría de los estudios se centra en el campo de la salud, siendo pocas las que se enfocan en la parálisis cerebral como procesos de inclusión escolar y social desde una mirada de los propios actores escolares que lo vivencian y construyen sus propios significados. He aquí un primer interés para desarrollar la investigación planteada.

Aunado a lo anterior, también había inquietudes que nacieron de experiencias en las prácticas profesionales donde se compartió con niños y niñas que vivían una situación de discapacidad en distintos ambientes escolares, de donde surgieron interrogantes como: ¿de qué manera son atendidos los niños con parálisis cerebral?, ¿̇cuáles serán sus sentimientos al compartir los mismos espacios con niños "normales"?, ¿en realidad aprenden los niños?, ¿en qué contribuye a que los niños asistan a clases?, ¿qué piensan los docentes acerca de incluir a niños con parálisis cerebral?, ¿cuál es la preparación de los maestros para atender educativamente a niños con parálisis cerebral? Las preguntas anteriores llevaron al origen de la pregunta central del proceso de investigación: ¿cuáles son los procesos de inclusión escolar vividos por una niña de grado tercero de primaria con parálisis cerebral en una institución educativa marginal de la ciudad de Popayán?

En este artículo presentaremos una de las categorías halladas fruto del proceso de investigación, titulada "El sujeto sin voz", que devela 
cómo la niña vive en una exclusión, incluso con ella misma, asunto que sigue cuestionando los procesos de inclusión escolar para la niñez en los contextos escolares.

\section{Metodología}

\section{Escenario y participantes de la investigación}

El escenario de investigación fue una institución pública urbano marginal ${ }^{11}$ de la ciudad de Popayán (Cauca), que cuenta con tres jornadas de atención (mañana, tarde y noche) y atiende a una población estudiantil de una de las comunas de la ciudad que presenta mayores problemáticas sociales como: consumo y venta de psicoactivos, prostitución, pandillas, delincuencia común, entre otros. Las familias pertenecen a un estrato socioeconómico cero o uno. La institución cuenta con una infraestructura amplia, de fácil acceso, con zonas verdes, una cancha de juego, baños clasificados para los estudiantes, restaurante escolar, sala de informática con escasos computadores; sus aulas son ventiladas e iluminadas, hay escasos materiales didácticos para atender estudiantes con alguna condición de discapacidad y no existen rampas para el desplazamiento a los salones y los demás espacios de la institución.

El sujeto central de la investigación es una estudiante en condición de discapacidad con parálisis cerebral, de contextura gruesa, estatura media, tez blanca, cabello largo, con un diagnóstico de hemiparesia espástica, definida esta por Salvador, Furtado, Alves dos Santos y Canarín (2012) de la siguiente manera: "Es afectada la extremidad superior e inferior de un mismo lado (por lo general la repercusión funcional es mayor en la extremidad superior), la espástica se caracteriza por tener un hemicuerpo casi siempre con mayor compromiso de la extremidad superior" (p.140).

Sus extremidades derechas están contraídas, presenta dificultad para hablar y caminar; se socializa poco con sus compañeros en el aula.

Se denominan zonas urbano marginales a aquellos lugares dentro de las ciudades que han sido olvidadas por las entidades gubernamentales y dentro de ellas convergen problemáticas sociales, económicas, laborales y educativas que pone a la población en situación de vulnerabilidad (Arteaga, 2005) 
La estudiante realiza sus estudios desde el grado de preescolar en la misma institución. Los docentes que han estado orientando su proceso educativo son normalistas y licenciados en educación, con treinta años de experiencia en docencia, pero sin experiencia en atención educativa a estudiantes en condición de discapacidad; los docentes son los encargados de orientar todas las áreas del conocimiento y rotan dentro de sus grupos; el grupo escolar donde se encuentra la niña tiene un total de 35 a 40 estudiantes.

La investigación es de corte cualitativo, porque busca comprender y describir los fenómenos sociales de acuerdo a cómo se observan y se presentan en la realidad de un proceso de inclusión educativa de una estudiante con parálisis cerebral en una institución pública marginal; tal y como lo plantea Strauss \& Corbin, (2002) "los métodos cualitativos se usan para obtener detalles complejos de algunos fenómenos, sentimientos, procesos de pensamientos y emociones, difíciles de extraer o de aprehender por métodos de investigación más convencionales" (p.21).

Entonces, la pretensión es comprender el fenómeno desde el interior de los sujetos participantes, develando aspectos como: los ambientes del contexto escolar, las actitudes, los sentimientos, los pensamientos, las experiencias, entre otros. El método utilizado para el desarrollo de la investigación es la teoría fundamentada, la cual, según Straus \& Corbin (2002), "es una teoría derivada de datos recopilados de manera sistemática y analizados por medio de un proceso riguroso de investigación” (p.21).

Las técnicas utilizadas para la recolección de la información fueron tres: la primera, la observación participante, que nos proporcionó información del comportamiento de la niña en interacción con su grupo social (Rojas, 1991); se utilizó el instrumento del diario de campo, apoyados también en registros fotográficos y audiovisuales. La segunda, la entrevista semiestructurada, que se fundamenta en la interrelación humana, combinando enfoques prácticos, analíticos e interpretativos implícitos en todo proceso de comunicación humana (Sandoval, 2014); 
esta técnica se aplicó a tres docentes (dos hombres y una mujer), empleando el instrumento de guía con preguntas abiertas. La tercera, el taller; se aplicaron talleres en el contexto escolar de la niña, utilizando como instrumento los planes guía; se hicieron registros fotográficos y audiovisuales. Estos talleres tuvieron como propósito sensibilizar y reflexionar con los participantes de la investigación frente a las actitudes y manifestaciones de inclusión o exclusión que estaban asumiendo con la estudiante.

De manera simultánea, en la aplicación de las técnicas de recolección de información se avanzó en la implementación de las técnicas de análisis de la información; para esto se utiliza el método de comparación constante, "que parte de la combinación del procedimiento de codificación propio del análisis de contenido y la generación de teoría propia de la inspección" (Strauss \& Corbin, 2002, p.174). El procedimiento de codificación cuenta con las siguientes fases: la codificación abierta, que consiste en nombrar los relatos y descubrir fenómenos y propiedades allí expuestos; la codificación axial, referida a la reagrupación de las categorías y subcategorías empíricas; la codificación selectiva, donde se describieron las categorías empíricas con sus subcategorías ya todas saturadas. Una vez terminado el proceso de codificación, se avanza hacia la triangulación de las categorías empíricas, donde convergen las teorías, las categorías empíricas y la voz del investigador, para así dar luz a la nueva teoría (Strauss \& Corbin, 2002, 175).

\section{Resultados}

Tal y como se ha señalado en la introducción, los resultados del proceso de investigación se articularán a partir de la categoría "El sujeto sin voz", la cual visibiliza las comprensiones de la realidad vivenciada por la niña, dentro del proceso de exclusión escolar; a continuación se despliegan los hallazgos de esta categoría.

Una de esas situaciones halladas es el poco conocimiento y reconocimiento que tiene la niña por parte de los distintos agentes educativos. Muestra de ello es que no existe ningún diagnóstico en la institución 
que advierta o dé pautas desde su condición. A este respecto, un docente expresa: "no hay un empalme por parte de las directivas donde nos den a conocer las problemáticas con que vienen los niños" (T: EP3/Re: A/G: M/R: $1 C$ ). Esto lleva a configurar unos métodos de enseñanza inapropiados, basados más en la intuición de los docentes que en auténticos ejercicios de valor pedagógico (Casanova y Rodríguez, 2009). Tampoco hay un proceso de acompañamiento escolar ni familiar por parte de agentes expertos para abordar aspectos importantes específicos de la formación de la niña, es decir, pareciera que con el acceso escolar bastara, como lo expresa el docente "no hay esa colaboración de nadie (...) es como uno solo tratando de hacer lo que se puede y con grupos tan numerosos es imposible llevar un buen proceso" (T: EP3/Re: A/G: M/R: 1D). Es así como el docente trata de enfrentar solo los retos que día a día le demanda el sistema educativo; muchas veces avanzando más hacia los errores que hacia una ruta pedagógica de inclusión que permita abordar una educación para todos (Arnaiz, 2012, p.25).

Otro asunto que se halló es la falta de formación que tienen los docentes frente a la atención educativa de la niña con parálisis cerebral; no se evidencian esfuerzos, ni preocupaciones, ni gestiones, ni conocimiento institucional de las políticas de inclusión educativa por hacer algo al respecto; el siguiente relato da cuenta de esto: "el rector nos dice que si hay diez estudiantes con discapacidad, él solicita el apoyo (...) yo no me siento preparado para enseñarle a la niña" (T: EP4/Re: A/G: M/R: 2B). El desconocimiento que enfrentan los docentes en el aula para atender a la niña, hace surgir sentimientos de incapacidad, miedo, frustración, inseguridad, rabia, entre otros; tal y como lo expresa el docente: "uno ya no sabe qué hacer, son tantas cosas por atender que uno se siente mal de no darle las cosas que ella necesita" (T: EP1/Re: A/G: M/R: 4C). La falta de formación y conocimiento de los docentes limita la generación de caminos, posibilidades y oportunidades para hacer transformaciones reales en el campo de la educación; se requiere, por tanto, maestros que desde la experiencia escolar desarrollen capacidades y habilidades para enseñar con calidad y mística ante las diversidades humanas (Blanco, 2006, p.13). 
Del mismo modo, por su forma de expresarse, los docentes evidencian tener poca sensibilización frente a la condición de la niña; para ellos, ella es una carga que les limita el trabajo con los demás estudiantes "normales"; incluso ven como la mejor opción que fuese retirada y llevada a un centro educativo especial, como lo refleja el siguiente relato: "lo ideal sería que la niña estuviera en un colegio apto para recibirla (...) allá sí hay educadores especiales" (T: EP3/Re: A/G: M/R: 12A). Esta falta de conocimiento y sensibilización por parte del docente, lleva a que mantenga acciones pedagógicas marcadas en la cotidianidad escolar por expresiones de exclusión (Calvo, 2013). Es así como hay ausencia de actividades diferenciadas para la niña, no hay preocupación por lo que la niña haga o deje de hacer; todo el tiempo la atención se centra en direccionar el proceso educativo con los demás estudiantes del aula, tal y como lo refiere el siguiente relato: "el docente empieza su clase (...) orienta todo igual para todos (...) al terminar la clase, la niña no había hecho nada (...) el docente no se dio cuenta" (T: OP/Re: DC1/G: G/R2).

Otro aspecto importante reflejado en la práctica pedagógica del docente que poco ayuda en el proceso de formación de la niña y de los demás estudiantes, es la prolongación de una educación bancaria, la cual, según Freire (1984), es la que se centra en contenidos para transmitir, control, disciplina sin oportunidades para crear y participar, disponiendo barreras para aprendizajes autónomos y significativos, el docente es el único poseedor del conocimiento, la enseñanza se centra en la transmisión de la información, hay una relación vertical docente-estudiante; esta situación queda consignada en el diario de campo: "en el salón se exige el silencio y la disciplina (...) pasa largo tiempo y el docente es el dueño de la palabra (...) todos los niños hacen lo mismo" (T: OP/Re: DC1/D/E1/R3A).

En este sentido, es frecuente ver al docente en su quehacer pedagógico privilegiando la memoria, repitiendo muchas veces la misma información y esperando a que los estudiantes la copien de igual manera; 
ellos no comprenden muchos conceptos que se conforman en replicar, como lo muestra el siguiente relato: "yo trato de repetirles muchas veces y preguntarles a ellos, y yo vuelvo les repito y les insisto en algo, y a los que están respondiendo y a los que están distraídos vuelvo me acerco, y les repito, vuelvo y les pregunto" (T: EP2/Re: A/G: M/R: 31). El docente tampoco utiliza recursos didácticos para apoyar sus clases, solo el tablero y al marcador, asunto que complica el proceso de aprendizaje para aquellos que poseen distintos estilos de aprendizaje, como lo refleja el siguiente relato: "el docente en todas sus clases ha utilizado solo como recurso el tablero y marcadores de color rojo, negro y azul" (T: OP/Re: DC3/D/R2A). Lo anterior nos muestra cómo, a pesar de los adelantos de la pedagogía actual, aún en los contextos escolares se vivencia una práctica pedagógica antigua alejada de los principios frente a los procesos que se requieren trabajar desde la inclusión (Acosta, 2005).

En la clase, el docente incentiva el trabajo individual y competitivo, es decir, solo algunos niños sienten que son capaces de hacer lo que pide el docente y son estimulados constantemente por él; por el contrario, los demás estudiantes que nunca logran ser los primeros en entregar o diligenciar lo que se les ha solicitado, reflejan inseguridad, baja autoestima y poca motivación por aprender, como lo indica la siguiente expresión: "los primeros que lo hagan tendrán un punto positivo" (T: OP/Re: DC4/E1/G/D/R4). De esta manera, en el aula se desconoce el principio de equidad (Liesa \& Vived, 2009); todos son tratados por igual; a esto se le suma que el docente asume actitudes y anhelos de homogenización en el grupo, desde el concepto de "normalidad", como lo expresa él mismo: "los otros niños, pues, son normales; ellos fácilmente captan todo lo que se les dice (....) van ahí desarrollando las cosas bien. En cambio, a ella se le dificulta porque ella no entiende cosas ya a mayor profundidad (...): entonces, esa sería una de las desventajas que ella tiene frente a el grupo" (T: EP3/Re: A/G: M/R: 7).

Ante el panorama anterior, la niña asiste a clase todos los días, pero nada es planeado, ni realizado pensando en ella; ella ocupa un espacio 
en la escuela pero es como si no existiera allí; se le señala más bien por lo que no puede hacer que por aquello que puede; ni el docente ni sus compañeros se han dado la oportunidad de descubrir sus capacidades; ha estado invalidada por mucho tiempo y, lo más triste, es que seguirá así, pues las características del entorno escolar que la acompaña no es muy estimulante y están lejos de reales transformaciones para llegar a una escuela inclusiva; por consiguiente, lo más seguro es que su proceso de desarrollo se quede cada vez más estancado, como lo expresa el relato: "sentada en el último puesto sola hace que está concentrada realizando su tarea (...), el profesor solo pasa cerca de su puesto y sus gestos expresan la poca importancia que le presta" (T: OP/Re: DC4/ E1/D/R2B). De este modo, se perpetúan los postulados de una educación integradora que expulsa y discrimina, sin la oportunidad de pertenecer a un grupo social con derechos, oportunidades y posibilidades de participación (UNESCO, 1994).

La niña aún no posee una competencia lingüística (Bustamante, 2010) que la lleve a comunicarse efectivamente a través del uso de una lengua oral o escrita; por esta razón, en las actividades de clase, que son mediadas por la oralidad, la lectura o la escritura (que son la gran mayoría), la niña queda totalmente aislada del grupo y tan solo se observa su rostro angustiado y su cuerpo esperando cualquier tiempo de atención; esto se refleja en el relato: "Hay veces que sí, sí hay veces que ella me responde y hay veces que ella dice no, que yo no hice, que yo no quise hacer eso y se queda así no más (...) La verdad es que no puedo comunicarme con ella y tampoco sus compañeros" (T: EP2/Re: A/G: M/R: 37). El docente también presenta sentimientos de frustración, manifestando en su práctica la imposibilidad de avanzar con la niña, por más esfuerzos que parece expresar: "cuando llamo a la niña para trabajar las dificultades, por ejemplo las combinaciones para que al menos escriba (...), le pregunto y ella no responde; esa es la situación que a ella todo se le olvida" (T: OP/Re: DC2/D: D1/R5C). Claramente se evidencia que el proceso educativo utilizado con la niña no es el adecuado. Estando el lenguaje ligado con el pensamiento, la escuela debe- 
ría recrear formas distintas de potenciar las capacidades de expresión y comunicación de la niña y de todos los demás educandos de acuerdo con sus posibilidades.

Pero, a pesar de lo anterior, las acciones del docente en su rutina escolar están centradas en el grupo de estudiantes "normales" y, si queda tiempo, se dedica a la niña; también la preocupación del docente es por los contenidos, el cumplimiento del horario escolar, la cantidad en vez de la calidad, la homogenización de los estudiantes; así lo expresan estos relatos:

\begin{abstract}
"Sí porque yo tengo que estar con todo el grupo y entonces escasamente sacar unos, unos minuticos para orientar a ella cositas muy sencillas para que haga" (T:EP3/Re: A/G: M/R: 9A); "porque eso es difícil uno dejar esos treinta y pico que hay (...) la niña de aquí ella es muy lenta, si uno se dedica a ella pues no hace nada con los demás" (T: EP2/Re: A/G: M/R: 20B).
\end{abstract}

Es así como el salón de clase aparece dividido entre los que aprenden, hacen y pueden, y los que no pueden, no hacen y no aprenden. El docente no implementa ninguna estrategia para garantizar los avances de cada uno de los niños, como se expresa en el relato: "Haber, pues yo los evalúo viendo el interés de ellos que tienen para hacer las cosas (...); a la hora de hacer ya la calificación definitiva, pues yo pienso en ellos y, de acuerdo a lo que he observado durante el periodo, es muy fácil" (T: EP2/Re: A/G: M/R: 28). Se puede entrever cómo se carece de procesos formativos no solo a nivel intelectual, sino también en el desarrollo de competencias emocionales y ciudadanas (Acosta y Arráez, 2014).

De esta manera, la niña no presenta avances; al no existir una flexibilización curricular, ni un plan adaptado que tenga en cuenta sus necesidades, el docente refuerza sus dificultades y ciegamente guía el proceso educativo con la niña:

"Repito, aquí ya hemos llenado un poco de cuadernos y tratando (...) tanto, tanto, tanto uno repetirle pues algo debe retenérsele (...); entonces, las ha olvidado; entonces, yo pienso: tanto yo fregar con ella con esas letras, pues yo creo que en algún momento tiene que comenzar a escribir y a leer" (T: EP3/Re: A/G: $\mathrm{M} / \mathrm{R}: 10 \mathrm{C})$. 
Ella, al no contar con un apoyo personalizado, en el que realmente se le reconozca en su diferencia, y desde allí se valore y se trabaje con lo que es capaz de hacer, se ha generado alrededor un ambiente de creencias frente a su incapacidad; por ende, en algunas ocasiones, unos pocos compañeros se apiadan de ella y le hacen lo que no es capaz de hacer: "una compañera de la niña le escribe en su cuaderno para que no se atrase; el profesor es indiferente ante la situación, nade les dice; él continúa escribiendo sin decirle nada" (T: OP/Re: DC2/D: D2/R4B). Se requiere urgente iniciar procesos de sensibilización frente a la discapacidad para avanzar hacia una cultura inclusiva real donde no se excluya ni por omisión, ni por sustitución (Infante, 2010).

Todos los aspectos escolares mencionados ocasionan tensiones familiares de distinta índole. La madre manifiesta angustia al ver y ser consciente de los pocos avances que demuestra la niña y, en ocasiones, pareciera que en vez de mejorar retrocediera: "uno se cansa de luchar contra todo (...), se siente como desfallecer (...) Es muy difícil cuando uno siente que su hija es como un problema en la escuela" (T: EP3/Re: A/G: M/R: 12). Frente a esto, el docente manifiesta poco interés, es indiferente frente a las problemáticas familiares, cree que está haciendo lo mejor para la niña y no evidencia ningún esfuerzo por cambiar todas la manifestaciones de exclusión escolar que él mismo proporciona en la clase: "son escasos minutos que a uno le quedan para tratar de que ella no esté ahí en esa desventaja (...), viendo trabajar los otros y ella de pronto sin nada” (T: EP3/Re: A/G: M/R: 9B); “entonces, sí, uno trata de como de entenderlas (...), de no molestarlas, que hagan lo que puedan porque tienen sus limitaciones (...)" (T: EP2/Re: A/G: M/R: 16B). Es así como la familia, siendo un elemento fundamental en la formación de un sujeto, también empieza a vivir un ambiente hostil y desolado, y siente tener poco apoyo por la institución escolar, asunto que incrementa las posibilidades de fracaso escolar (Gómez, 2005).

Ante el panorama anterior, la niña en el aula es tan solo una espectadora de todo lo que sucede en su ambiente escolar; poco interactúa con los demás y poco los demás advierten la presencia de ella: "su aten- 
ción sostenida observa todo a su alrededor, su interacción es mínima, sus compañeros inconscientemente la invisibilizan de toda actividad escolar" (T: OP/Re: DC4/E/D/R2A). De este modo se evidencia cómo en el aula de clase se construyen barreras de participación, tanto del docente como de sus compañeros: "ella no puede dar más (...); con que aprenda las cuatro operaciones y leer y escribir yo creo que ya es mucho (...); es muy difícil tenerla acá en la clase sin saber cómo" (T: EP3/ Re: A/G: M/R: 8A). Es aquí donde se evidencia que el trabajo escolar frente a la inclusión debe iniciar por derrumbar esas representaciones sociales que se crean y que determinan formas de pensar y de actuar frente a un aspecto específico (Vesga y Vesga, 2015).

Con todas las vivencias de exclusión escolar y sin nadie que pueda brindarle un apoyo educativo distinto, la niña se muestra resignada; a veces se entretiene sola ante la invisibilidad ocasionada por el mismo contexto escolar. Sentada en la última silla del salón, la niña es alejada de todo y de todos; su silencio la invade y opaca todo su ser: "la niña pierde su mirada en un punto fijo y allí pensativa, ausente (T: OP/Re: DC2/E: E1/R2A); "la mayoría de veces está sola, es la única que no cuenta con un amigo a su lado como todos los demás; la razón del docente es que se distrae" (T: OP/Re: DC4/E1/D/R2B). Se observa, en consecuencia, cómo, sin poder avanzar en su pensamiento y lenguaje, la niña se empieza a autoexcluir, como lo explica Suriá (2014):

La causa de esto se constituye por comportamientos aprendidos en el contexto que remite a clasificar, homogenizar y segregar a las personas por sus diferencias, hasta tal punto que estos comportamientos son naturalizados por todos, incluso por el sujeto que es discriminado.

Es así como la niña se encuentra en un entorno cruel, donde a nadie le importa lo que le sucede; pareciera que eso de la educación para todos es aquí un espejismo inalcanzable. Cuando la niña se atreve a preguntar o a interesarse por algo, no recibe de nadie una retroalimentación, es como si estuviera condenada a esperar ver pasar el tiempo sentada en una silla, para luego irse a casa: 
"pregunta afanada por el ejercicio del tablero (...); el profesor no la escucha; ella se calla y se queda sentada observando a los demás" (T: OP/Re: DC4/E1/R3A). "El docente revisa todos los cuadernos de ciencias (...), menos el de la niña" (T: $\left.\mathrm{OP} / \mathrm{Re}: \mathrm{DC} 3 / \mathrm{D} / \mathrm{D} / \mathrm{R}_{3} \mathrm{~A}\right)$. "Hoy la actividad era en grupos (...), todos se organizaron rápidamente, la niña observó cómo la única que quedaba sola fue ella" (T: EP2/Re: A/G: M/R: 41).

En este sentido, Andrade (2011) explica cómo la educación tradicional propicia brechas de separación de los niños "normales" y los "especiales", dada por la incapacidad del sistema educativo para atender y respetar las particularidades de cada uno, las cuales imposibilitan que ambas poblaciones compartan los mismos espacios y oportunidades.

A pesar de todas las manifestaciones diarias de discriminación y exclusión que recibe la niña por parte de sus compañeros y docente, se evidencia los esfuerzos que ella hace para lograr una integración con los demás, como se manifiesta en estos relatos: "En ocasiones la niña se esfuerza para hablar con una amiga que le ayuda cuando se queda atrasada” (T: OP/Re: DC3/E: /R1B); "a pesar de su limitación en la parte derecha del cuerpo se esfuerza por seguir algunos ejercicios orientados por el profesor" (T: OP/Re: DC4/E1/R3B). Sus compañeros interactúan con ella solo cuando la van a poner al día con actividades que ha dejado incompletas o sin hacer, o cuando ella lleva objetos distintos a clase para que se los preste, es decir, amistades por conveniencia, pero no para relacionarse, compartir, dialogar, jugar, entre otras, como se describe en el diario de campo: "los compañeritos ayudan a buscar el cuaderno para escribirle la nota que pidió el profesor" (T: OP/Re: DC1/D/G: G/R4A); "¿quién hace los dibujos a la niña? Pregunta el docente (...) Todos los niños levantan la mano" (T: OP/D: DC7/G: G/Re: R4B). Se dice que la escuela cumple un papel socializador (Zambrano, 2001), pero para este caso ni esto se cumple en la estudiante en condición de discapacidad.

Haciendo un análisis de los procesos de interacción que vive la niña con sus compañeros, se llega a la conclusión que se aleja de amistades donde ambas personas de fortalecen y se enriquecen; los contactos no pasan de entretener a la niña esporádicamente y de prestarle una ayuda para que el docente considere que ella no es capaz: "a veces una niña 
la llama y le muestra muñecos para que se ría” (T:OP/Re: DC2/D: D2/ R4B); "siempre ayudamos a la niña a lo que ella no es capaz" (T:OP/ Re: DC2/D: D2/R13B). Todo lo anterior ha generado una gran inseguridad en la niña frente a sus capacidades y su autoestima, pues, ante actividades grupales como fiestas y dinámicas, se niega rotundamente en participar, asunto que para sus compañeros les es indiferente:

\begin{abstract}
"Le dio pavor participar en la actividad grupal (...) corrió hacia la parte de atrás, y con su mano derecha se escondió en su mesa" (T: OP/D: DC7/E: E1/Re: R3). "La llamamos y ella no quiere salir, notamos que le da pena, inseguridad, y la respuesta es no sé" (T: OP/D: DC5/E: E1/Re: R4A); "sale la compañera pero ella no quiere salir, parece que siente pena de pararse y caminar hasta el centro del salón" (T: OP/D: DC6/E: E1/Re: R4B).
\end{abstract}

Por lo anterior, la escuela se convierte en un espacio que, antes que posibilitar, limita esas dimensiones a desarrollar en cualquier ser humano, privándole sus derechos fundamentales (Echeita, 2013).

Las acciones de exclusión que, de alguna manera, se han naturalizado en el aula de clase por el docente, son replicadas en las actitudes que presentan los compañeros de la niña, a pesar de llevar cuatro años compartiendo con ella; ellos no saben qué es lo que tiene la niña ni cómo pueden relacionarse con ella, ni mucho menos cómo pueden realmente ayudarla sin inutilizarla, es decir, se carece de una sensibilización y conocimiento del asunto de la parálisis cerebral por todos los agentes de la comunidad educativa que rodea a la niña, como se describe en el diario de campo: "a ella no sé qué le pasa porque ni es igual a nosotros" (T: OP/D: DC7/G: G/Re: R2A); "profe, ella no, porque tiene infección y se me pasa a mí (...); a ella siempre se le hace todo porque no es capaz de hacer nada" (T: OP/D: DC7/G: G/Re: R5B). Mientras que estos sucesos no sean conscientes por parte de los sujetos escolares, no habrá ningún cambio y, por el contrario, se tenderá a empeorar las manifestaciones de exclusión (Pérez, 2011).

De esta manera, ni la niña ni los compañeros han desarrollado una empatía, pues ambos desconocen lo que pasa. En tal sentido, la niña, como un mundo aparte, se retrae, se inhibe, pasa inadvertida, presenta 
gestos de miedo, inseguridad y tristeza; en su mirada es como si deseara ser como los otros, como se evidencia en los relatos: "La tomamos de la mano y la llevamos para que forme el grupo; ella se sonríe pero se toma de la mano de nosotros fuerte y no se suelta; se termina y se sienta” (T: OP/D: DC6/E: E1/Re: R4C). "No participa del juego, permanece sentada y expresa no querer hacerlo" (T: OP/D: DC6/G: G/Re: R3). No se ha construido en el aula una educación desde la diferencia, por esto lo distinto es raro y no cabe en el grupo humano; la niña vive alejada, ausente y apartada, como se describe en el diario de campo: "a preguntas en grupo se queda en silencio y después de un rato dice: no sé" (T: OP/D: DC5/E: E1/Re: R4A); "no quiere salir porque siente pena, no quiere salir con su cabeza moviéndola varias veces y colocándose roja dice: no, no, no, no”.(T: OP/D: DC8/E: E1/Re: R3B)

Partiendo del trabajo de Jiménez y Gaete (2013), donde se expresa que los motivos fuertes para permanecer en la escuela son los vínculos con el grupo y amigos, ya que hacen parte del aprendizaje, de la construcción del desarrollo de personalidad, y para la vida social en general, vemos aquí que pareciera que cualquier otro lugar es el más adecuado para la formación de la niña, menos la escuela. Para finalizar la categoría desarrollada, es importante dejar claro que la niña está sumergida en un ambiente de exclusión por parte de los directivos, de los docentes, de los compañeros, donde seguramente si no se hace una sensibilización y reflexión de lo que está sucediendo, pasarán muchos años más ocasionándole graves problemas emocionales a la niña con parálisis cerebral y, en últimas, robándole lo más preciado que es su voz y la posibilidad de desarrollarse como ser humano, sin importar la condición en la que se encuentra.

\section{Conclusiones}

A pesar de las políticas públicas divulgadas en los últimos años sobre inclusión educativa frente a poblaciones vulnerables, como son los niños y niñas en situación de discapacidad, se siguen perpetuando en los escenarios escolares procesos de exclusión escolar que detonan a 
futuro en una exclusión social (Jiménez, Luengo y Taberner, 2005). Es así como las instituciones educativas a las que la ley presiona para recibir estudiantes en condición de discapacidad, si bien garantizan un acceso y, tal vez, una permanencia, esto se hace a costa de la calidad y los procesos formativos significativos de los niños y niñas vulnerables (Suriá, 2012).

Un aspecto decisivo para llegar a procesos de inclusión educativa es la formación de los docentes, pues son ellos quienes deben crear y disponer ambientes de aprendizajes efectivos y afectivos para garantizar los aprendizajes a sus estudiantes, en especial para aquellos que presentan una condición de discapacidad. Otro aspecto relevante es la generación de procesos de sensibilización escolar frente a la diversidad, a la manera como a los ciudadanos se les puede garantizar oportunidades y posibilidades para todos, de tal forma que se cumpla lo expresado en la Constitución Política de Colombia (1991) frente a la eliminación a cualquier forma de discriminación.

Igualmente, en los ambientes escolares falta avanzar hacia el aumento del índice de inclusión educativa (MEN, 2008), de manera que se evidencie, en todos los estamentos de los centros escolares, un trabajo real desde las distintas gestiones: directiva, académica, administrativa y comunitaria, para que se garantice realmente un cambio de las distintas barreras físicas, mentales y emocionales que han sido reconfiguradas socialmente frente a las personas que presenten alguna discapacidad. De este modo, las instituciones educativas serán las llamadas a repensar de forma diferenciada sus currículos, sus prácticas pedagógicas, sus formas de evaluar y demás actividades propias de la escuela, que lleven a responder a un mundo diverso y pluricultural como el que habitamos.

También es necesario que la institución escolar se convierta en un apoyo en el proceso formativo que desde la familia se les imparte a los niños en situación de discapacidad; de lo contrario, los esfuerzos de todos estarían desarticulados y seguramente los avances serían pocos y lentos. Las entidades gubernamentales y las políticas nacionales deben asegu- 
rar que los docentes que están guiando los procesos educativos de los estudiantes con cualquier discapacidad cuenten con las competencias necesarias para hacerlo, garantizándoles no solo el acceso y la permanencia en el sector educativo, sino también la calidad del servicio.

Esta investigación permite evidenciar cómo en la actualidad se siguen vulnerando los derechos fundamentales de los niños con discapacidad, y cómo estos casos, que no son aislados en las regiones periféricas de Colombia, como lo es Popayán, requieren una mirada reflexiva para iniciar procesos de cambio de todos los actores involucrados directa e indirectamente para avanzar hacia la práctica de los discursos de la inclusión educativa y social.

\section{Referencias}

Acosta, A., y Arráez, T. (2014). Actitud del docente de educación inicial y primaria ante la inclusión escolar de las personas con discapacidad motora. Revista de Investigación, 38(83), 135-154. Recuperado de http://www.scielo.org.ve/pdf/ ri/v38n83/arto8.pdf

Acosta, M. (2005).Tendencias pedagógicas contemporáneas. La pedagogía tradicional y el enfoque histórico cultural. Análisis comparativo [en línea]. Revista Cubana Estomatología, 42(1). Recuperado de http://scielo.sld.cu/scielo. php?pid=So034-75072005000100009\&script=sci_arttext

Andrade Ruíz, F. (2011). La inclusión educativa en el aula regular un caso de síndrome de Asperger. Revista electrónica Educare, 15(Número extraordinario), 39-53. Recuperado de http://www.redalyc.org/articulo.oa?id=194121530004

Arnaiz, S. P. (2012). Escuelas eficaces e inclusivas, como favorecer su desarrollo. Educatio Siglo XXI, 3o(1), 25-44. Recuperado de http://revistas.um.es/educatio/ article/view/149121/132111 
Arteaga, I. (2005). De periferia a ciudad consolidada estrategias para la transformación de zonas urbanas marginales. Revista Bitácora Urbano Territorial, 9(1), 98-111. Recuperado de http://www.redalyc.org/pdf/748/74800909.pdf

Blanco, G. R. (2006). La equidad y la inclusión social: Uno de los desafíos de la escuela de hoy. REICE - Revista electrónica iberoamericana sobre calidad, eficacia y cambio en educación, 4(3), 1-15. Recuperado de http://www.redalyc.org/ articulo.oa?id=55140302

Blanco, R., Aguerrondo, I., Ouane, A., y Shaeffer, S. (2000). La Educación inclusiva: El camino hacia el futuro una breve mirada a los temas de educación inclusiva: aportes a las discusiones de los talleres. Conferencia internacional de educación, organización de las naciones unidas para la educación, la ciencia y la cultura. Ginebra. Recuperado de http://www.ibe.unesco.org/fileadmin/user upload/Policy_Dialogue/48th_ICE/CONFINTED_48_Inf_2__Spanish.pdf

Bustamante Zamudio, G. (2010). Competencia Lingüística y Educación. Folios, 31, 81-90. Recuperado de http://revistas.pedagogica.edu.co/index.php/RF/article/viewFile/896/925

Calvo, G. (2013). La formación de docentes para la inclusión educativa. Páginas de educación, 6(1), 19-35. Recuperado de http://www.scielo.edu.uy/scielo. php?pid=S1688-74682013000100002\&script=sci_arttext

Canarin, M., Furtado, E., Alves, K., y Pedroso, F. (2012). La representación social de cuidadores de niños y adolescentes con parálisis cerebral hemipléjica. Subjetividad y procesos cognitivos, 16(1), 135-147. Recuperado de http://www. redalyc.org/articulo.oa?id=339630259006

Comín, D. (2014). Transformando la educación especial en educación inclusiva. Autismo diario. Recuperado de http://autismodiario.org/2014/12/o3/transformando-la-educacion-especial-en-educacion-inclusiva/

Echeita, G. (2013). Inclusión y exclusión. "Voz de quebranto". Revista iberoamericana sobre calidad, eficacia y cambio en educación, 11(2), 99-118. Recuperado de http://www.redalyc.org/articulo.oa?id=55160202 
François, R., y Martínez E. (2005). Osteopatía y Pediatría. Madrid: Médica panamericana.

García, L., y Restrepo, S. (2010). La Alimentación del Niño con Parálisis Cerebral un Reto para el Nutricionista Dietista. Perspectivas desde una Revisión. Perspectivas en Nutrición Humana, 12(12), 78-79. Recuperado de http://www.scielo. org.co/pdf/penh/v12n1/v12n1a

Gómez, J. (2005). Pautas y estrategias para entender y atender la diversidad en el aula. Pulso, 28, 199-214. Recuperado de dialnet.unirioja.es/descarga/articulo/1370936.pdf

Infante, M. (2010). Desafíos a la formación docente inclusión educativa. Estudios pedagógicos, 36(1), 287-297. doi: 10.4067/So718-07052010000100016

Jiménez, M., Luengo, J., y Taberner, J. (2005). Exclusión social y exclusión educativa como fracasos. Conceptos y líneas para su comprensión e investigación. Curriculum y formación del profesorado, 13(3), 1-39. Recuperado de http://www. ugr.es/ recfpro/rev133ART1.pdf

Jiménez, W., y Gaete, M. (2013). Estudio de la exclusión educativa y abandono en la enseñanza secundaria en algunas instituciones públicas de Costa Rica. Educare, 17(1), 105-128. Recuperado de http://www.scielo.sa.cr/scielo.php?script=sci_arttext\&pid=S1409-42582013000100007

Liesa, M., y Vived, E. (2009). Desarrollo de las competencias de los maestros en atención a la diversidad a través del diseño de escenarios de inclusión social. Revista argentina de psicopedagogía, 62, 1-22. Recuperado de dialnet.unirioja.es/descarga/articulo/3045261.pdf

Madrigal, A. (2004) La parálisis cerebral. Madrid: Instituto de mayores y Servicios Sociales, Observatorio de la discapacidad.

Mantoan, M. T. (2005). A hora da virada. Inclusão: revista de educação especial, 1(1), 24-28. Recuperado de http://www.histedbr.fe.unicamp.br/acer_histedbr/seminario/seminario7/TRABALHOS/N/Nerli\%2ononato\%20ribeiro\%2omori.pdf 
Ministerio de Educación Nacional (2008). Programa de educación inclusiva con calidad "construyendo capacidad institucional para la atención de la diversidad". Bogotá: MEN. Recuperado de http://www.colombiaaprende.edu.co/html/ micrositios/1752/articles-320693_Pdf_1.pdf

Pérez, M. (2011). Violencia Escolar y Rendimiento Académico (VERA): aplicación de realidad aumentada. Education and Psychology. 1(2), 71-84. doi: //dx.doi. org/10.1989/ejihpe.v1i2.6

República de Colombia (1991). Constitución política de Colombia. Bogotá: Gobierno Nacional. Recuperado de http://www.procuraduria.gov.co/guiamp/media/ file/Macroproceso\%2oDisciplinario/Constitucion_Politica_de_Colombia.htm República de Colombia (1994). Ley General de Educación. Bogotá: Gobierno Nacional. Recuperado de http://www.mineducacion.gov.co/1621/articles-85906_ archivo_pdf.pdf ley115

Rojas Soriano, R. (1991). Guía para realizar investigaciones sociales. México: Plaza y Valdés.

Rubinstein, S., Ramalho M., \& Camargo Netto, F. (2002). O desenvolvimento da criança com Paralisia Cerebral no ambiente familiar. Movimento, 8(3), 33-45. Recuperado de http://www.redalyc.org/pdf/1153/115318050004.pdf

Saldarriaga, O. (2009). La escuela colombiana hace 200 años, al derecho y al revés. En Ministerio de Educación Nacional, Colección Bicentenario 11, Relatos para volver a contar. (pp. 9-15). Bogotá: MEN.

Salvador, F., Furtado, E., Alves dos Santos, K., y Canarín, M. (2012). La representación social de cuidadores de niños y adolescentes con parálisis cerebral hemipléjica. Subjetividad y Procesos Cognitivos, 16(1), 135-147. Recuperado de http://www.scielo.org.ar/pdf/spc/v16n1/v16n1ao6.pdf

Sandoval, A. (2014). La entrevista en la investigación de campo: de la observación a la escucha. Recuperado de https://prezi.com/g3actag69-yu/la-entrevista-en-la-investigacion-de-campo-de-la-observacio/ 
Sarto, M., y Venegas, M. (2009). Aspectos clave de la Educación Inclusiva. Kadmos: Salamanca.

Strauss, A., \& Corbin, J. (2002). Bases de la investigación cualitativa. Técnicas y procedimientos para desarrollar la teoría fundamentada. Medellín: Universidad de Antioquia.

Suriá Martínez, R. (2012). ¿Se sienten integrados los estudiantes con discapacidad en su centro educativo? Análisis función de discapacidad y etapa formativa. $\mathrm{Cu}$ rriculum y formación del profesorado, 16(3), 1-16. Recuperado de: rua.ua.es/ dspace/bitstream/10045/25975/1/rev163COL7.pdf

UNESCO (1994). Conferencia Mundial sobre Necesidades Educativas Especiales. Madrid: Ministerio de educación y ciencia. Recuperado de http://unesdoc. unesco.org/images/oo11/o01107/110753so.pdf

UNICEF (2001). Inclusión de Niños con Discapacidad en Escuela Regular. Santiago de Chile: UNICEF. Recuperado de http://portales.mineduc.cl/usuarios/edu. especial/doc/201304151207310.doc_Inclusion_Unicef.pdf

Vesga, L. y Vesga, J. (2015). Una exclusión que se perpetúa: tensiones entre docentes, niños sordos y niños oyentes en escenarios escolares de Popayán. Revista Virtual Universidad Católica del Norte, 46, 115-128. Recuperado de http:// redalyc.org/articulo.oa?id=194242285010 $>$ ISSN 0124-5821

Zambrano Leal, A. (2001). La mirada del sujeto educable: la pedagogía y la cuestión del otro. Santiago De Cali: Nueva biblioteca pedagógica. 